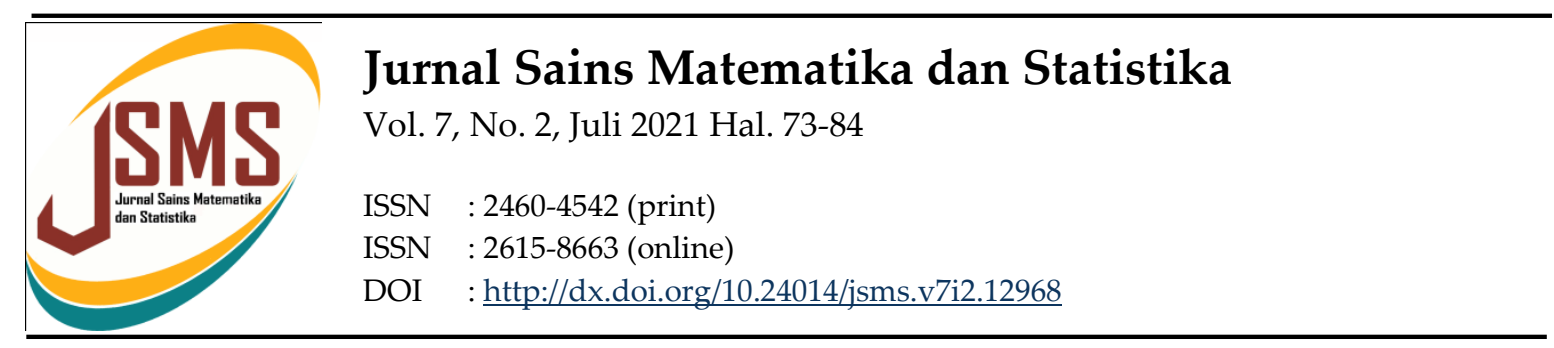

\title{
Penerapan Metode Analytical Hierarchy Process dalam Menentukan Gaji Bonus Karyawan pada PTPN III Sei Putih
}

\author{
Radita Fadillah' ${ }^{1}$, Sajaratud Dur ${ }^{2}$, Hendra Cipta ${ }^{3}$ \\ 1,2 Prodi Matematika, Universitas Islam Negeri Suamtera Utara Medan \\ Jl. IAIN No. 1 Kec. Medan Timur, Kota Medan \\ ${ }_{3}^{3}$ Prodi Matematika, Universitas Islam Negeri Sumatera Medan \\ Jl. IAIN No. 1 Kec. Medan Timur, Kota Medan \\ Email_Raditafadillah1707@gmail.com ${ }^{1}$, sajaratuddur@uinsu.ac.id² ${ }^{2}$ hendracipta@uinsu.ac.id $^{3}$
}

\begin{abstract}
Abstrak
Karyawan merupakan bagian terpenting di dalam perusahaan. Berdirinya suatu perusahaan tergantung pada karyawan, dimana kinerja karyawan dibutuhkan oleh perusahaan demi menunjang keberhasilan suatu perusahaan. Setiap karyawan pasti memiliki kriteria itu antara lain adalah absensi, disiplin kerja, tanggung jawab, percaya diri dan kerja sama. namun ada masalah untuk menentukan urutan prioritas pada gaji bonus para karyawan, karena nilai kriteria pada gaji bonus karyawan berbeda-beda sehingga penelitian menjadi sebuah penelitian penulis. Tujuan dari penelitian ini adalah mengetahui bagaimana penerapan metode Analytical Hierarchy Process (AHP) dalam menentukan urutan prioritas pada gaji bonus di PT. Perkebunan Nusantara (PTPN) III Sei Putih. Berdasarkan perhitungan yang telah dilakukan, maka urutan prioritas pada gaji bonus karyawan di PTPN III Sei Putih adalah percaya diri $(0,336)$, disiplin kerja $(0,221)$, kerja sama $(0,214)$, absensi $(0,176)$, tanggung jawab $(0,109)$.
\end{abstract}

Kata Kunci : Sistem pendukung keputusan, Analytical Hierarchy Process (AHP).

\begin{abstract}
Employees are the most important part in the company. The establishment of a company depends on employees, where employee performance is needed by the company to support the success of a company. Every employee must have these criteria, including absenteeism, work discipline, responsibility, confidence and cooperation. but there is a problem to determine the order of priority on the bonus salaries of employees, because the value of the criteria on employee bonus salaries is different so that the research becomes a research writer. The purpose of this study was to find out how the application of the Analytical Hierarchy Process (AHP) method in determining the order of priority on bonus salaries at PT. Nusantara Plantation (PTPN) III Sei Putih. Based on the calculations that have been made, the priority order for employee bonus salaries at PTPN III Sei Putih is confidence (0.336), work discipline $(0.221)$, cooperation $(0.214)$, attendance $(0.176)$, responsibility (0.109).
\end{abstract}


Keywords: Analytical Hierarchy Process (AHP), decision support system.

\section{Pendahuluan}

PT. Perkebunan Nusantara III (Persero) disingkat PTPN III menjadikan minyak dan inti sawit serta karet sebagai komoditi utama yang memberikan kontribusi besar bagi pendapatan perusahaan. Pada produk minyak dan inti sawit yang dihasilkan perusahaan sudah dikenal di pasar lokal dan Internasional dengan pasokan yang tepat waktu kepada pembeli dengan mutu yang dihasilkan Crude Palm Oil (CPO), Palm Kernel Oil (PKO), Palm Kernel (PK) dan Palm Kernel Meal (PKM). Pada karet di seantero dunia, Sumatera dikenal sebagai penghasil karet bermutu tinggi.Mutu produksi RSS-1, SIR-10, SIR-20 dan Lateks disejumlah pabrik ban terbesar seperti Bridgestone, Good Year, Firestone,HanKookdan lainnya (http://www.ptpn3.co.id/biskakbn.php?h=bisnis-kami).

Karyawan merupakan bagian terpenting didalam perusahaan, dimana sukses tidak sesuatu perusahaan tergantung pada kinerja setiap karyawannya, untuk menjaga kestabilan kinerja karyawan agar selalu semangat dan termotivasi. Perusahaan memberikan motivasi karyawannya dengan pemberian award yang diberikan dalam periode tertentu misalkan dengan bonus sesuai dengan kriteria yang telah ditentukan oleh perusahaan oleh para pengambil keputusan. Hanya dengan point yang baik yang bisa mendapatkan bonus, tetapi apakah karyawan yang diberikan bonus memang sesuai dengan hasil kerja apa tidak [6].

Gaji bonus adalah pembayaran tambahan di luar upah atau gaji yang ditujukan untuk memacu (memberi insentif) agar pekerja dapat menjalankan tugasnya lebih baik dan penuh tanggung jawab, dengan harapan keuntungan lebih tinggi. Makin tinggi keuntungan yang diperoleh makin besar bonus yang diberikan pada pekerja [2].

Dengan demikian hal ini menimbulkan dampak masalah terhadap perusahaan dalam menentukan urutan prioritas pada gaji bonus karyawan, karena karyawan memiliki kinerja yang berbeda-beda. Perusahaan bertindak dalam menentukan urutan gaji bonus. Perusahaan memiliki kriteria kriteria tertentu antara lain adalah absensi, disiplin kerja, tanggung jawab, percaya diri dan kerja sama.Berdasarkan kelima kriteria tersebut perusahaan dapat menentukan urutan gaji bonus karyawan.

Dalam hal ini, penulis menggunakan Metode Analytic Hierarchy Process (AHP) untuk menentukan urutan gaji bonus karyawan sehingga didapat hasil yang diinginkan perusahaan dalam mencari solusi dalam permasalahan mengambil keputusan secara ilmiah dan dibuktikan menggunakan metode matematis.

Metode Analytic Hierarchy Process (AHP) merupakan sebuah metode yang memodelkan permasalahan kompleks dan tidak terstruktur ke dalam bentuk permasalahan secara bertingkat/berjenjang, kemudian elemen-elemen pada setiap tingkatan akan diberikan penilaian secara kualitatif subjektif. Metode ini cukup banyak digunakan untuk menyelesaikan permasalahan yang berhubungan dengan pengambilan keputusan atau kelayak suatu usaha.

Peneliti bertujuan untuk membantu kebenaran urutan prioritas pada gaji bonus karyawan, Sehingga dapat di harapkan membantu PT. Perkebunan Nusantara (PTPN) III Sei Putih dalam menentukan kebenaran urutan prioritas pada gaji bonus karyawan. 


\section{Landasan Teori}

\subsection{Pengertian Gaji}

Gaji merupakan suatu bentuk pembayaran periodik dari seorang majikan pada karyawan yang dinyatakan dalam suatu kontrak kerja.Dari sudut pandang pelaksanaan bisnis, gaji dapat dianggap sebagai biaya yang dibutuhkan untuk mendapatkan sumber daya manusia untuk menjalankan operasi, dan karenanya disebut dengan biaya personel atau biaya gaji.Dalam akuntansi, gaji dicatat dalam akun gaji. Istilah lain dari gaji adalah honor dan upah. Gaji, honor atau pun upah dapat diterima pegawai di lingkungan kantor atau tempat kerja milik negara atau tempat swasta [2].

\subsection{Pengertian Upah}

Upah merupakan salah satu sumber penghasilan bagi pekerja untuk memenuhi kebutuhan hidupnya secara layak. Hak atas upah timbul dari perjanjian kerja dan merupakan salah satu hak dalam hubungan kerja. tersebut [5].

\subsection{Pengertian Gaji Bonus}

Gaji bonus adalah pembayaran tambahan di luar upah atau gaji yang ditujukan untuk memacu (memberi insentif) agar pekerja dapat menjalankan tugasnya lebih baik dan penuh tanggungjawab, dengan harapan keuntungan lebih tinggi.Makin tinggi keuntungan yang diperoleh makin besar bonus yang diberikan pada pekerja.Tidak semua perusahaan di Indonesia memberikan gaji bonus kepada karyawan. Gaji bonus ini biasanya dikeluarkan atas inisiatif dari pemimpin perusahaan [2].

\subsection{Pengertian Karyawan}

Karyawan merupakan bagian terpenting didalam perusahaan, dimana sukses tidak sesuatu perusahaan tergantung pada kinerja setiap karyawannya, untuk menjaga kestabilan kinerja karyawan agar selalu semangat dan termotivasi. Perusahaan memberikan motivasi karyawannya dengan pemberian award yang diberikan dalam periode tertentu misalkan dengan bonus sesuai dengan kriteria yang telah ditentukan oleh perusahaan oleh para pengambil keputusan. Hanya dengan poin yang baik yang bisa mendapatkan bonus, Tetapi apakah karyawan yang diberikan bonus memang sesuai dengan hasil kerja apa tidak [6].

\subsection{Pengertian AHP}

AHP (Analitycal Hierarchy Process) merupakan metode untuk membantu mengambil suatu keputusan tertentu yang sesuai dengan kriteria. Untuk mebantu perhitungan metode AHP ini ditentukan sebuah bobot pada setiap kriteria agar lebih mudah dalam perhitungan selanjutnya [7].

\section{Metodologi Penelitian}

\subsection{Target/subjek/sumber/variabel penelitian}

Target penelitian adalah karyawanPT. Perkebunan Nusantara (PTPN) III Sei Putih, Galang, Deli Serdang, Sumatera Utara. Jenis dan sumber data yang digunakan dalam penelitian ini adalah data primer. Variabel penelitian adalah absen, disiplin kerja, tanggung jawab, percaya diri, kerjasama. 


\subsection{Prosedur Penelitian}

Prosedur yang akan dilakukan pada penelitian ini adalah :

1. Mengumpulkan data dari perusahaan berkaitan kinerja karyawan pada PT. Perkebunan Nusantara (PTPN) III Sei Putih

2. Melakukan analisis data dengan menggunakan metode (AHP) yaitu :
a. Melakukan wawancara untuk mendapatkan data yang diperlukan
b. Menyusun hirarki permasalahan
c. Membuat matriks perbandingan
d. Melakukan sintesis
e. Menentukan nilai total rangkingmasing-masing variabel

\section{Hasil dan Pembahasan}

\subsection{Perhitungan AHP :}

1. Menyusun Hirarki Permasalahan

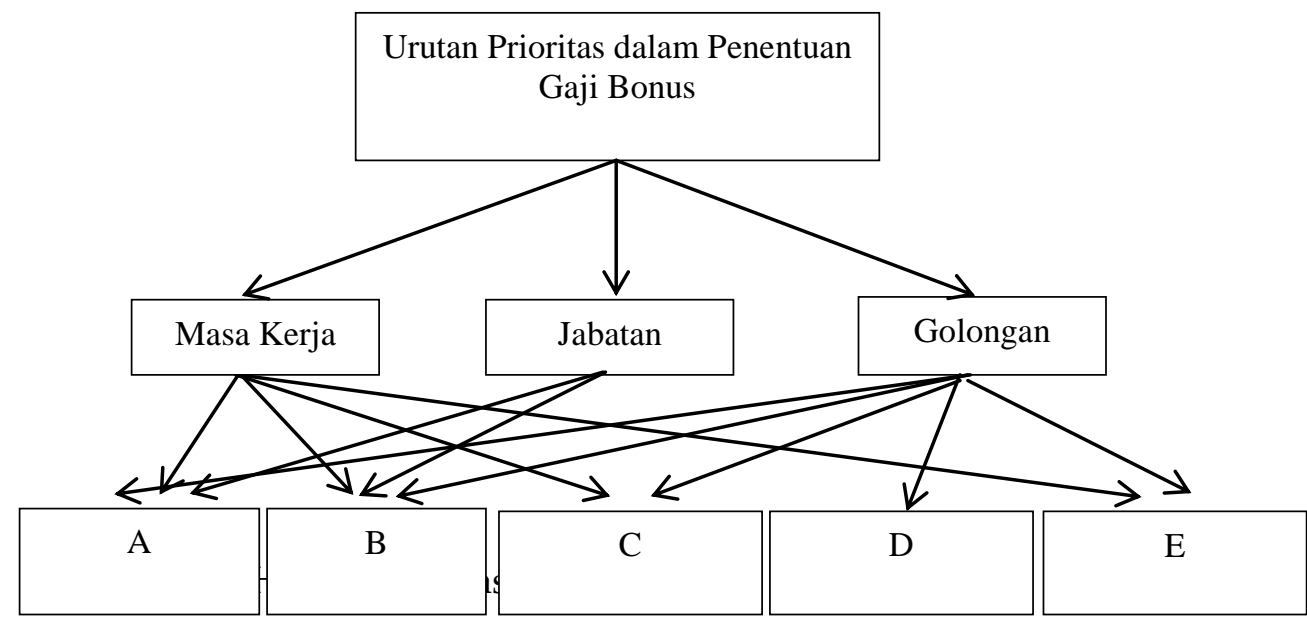

Gambar 1. Hirarki Pemasalahan

Keterangan :

$\mathrm{A}=$ Absensi

$\mathrm{B}=$ Disiplin Kerja

$\mathrm{C}=$ Tanggung Jawab

$\mathrm{D}=$ Percaya Diri

$\mathrm{E}=$ Kerja Sama

2. Menentukan Matriks Perbandingan untuk Kriteria.

Dari hasil analisis wawancara yang dilakukan menunjukan bahwa kriteria masa kerja lebih penting dari kriteria jabatan, kriteria masa kerja sedikit lebih penting dari kriteria dari kriteria golongan dan kriteria golongan sedikit lebih penting dengan kriteria jabatan. 
Tabel 1. Matriks Perbandingan Untuk Kriteria

\begin{tabular}{cccc}
\hline & Masa Kerja & Jabatan & Golongan \\
\hline Masa Kerja & 1 & 5 & 3 \\
Jabatan & $1 / 5$ & 1 & $1 / 3$ \\
Golongan & $1 / 3$ & 3 & 1 \\
\hline
\end{tabular}

Sumber : Wawancara dengan pimpinan.

Berdasarkan hasil dari Tabel 1 diatas sehingga diperoleh tabel 2 seperti yang terlihat dibawah ini :

Tabel 2. Matriks Perbandingan untuk Kriteria yang Disederhanakan

\begin{tabular}{cccc}
\hline & Masa Kerja & Jabatan & Golongan \\
\hline MasaKerja & 1 & 5 & 3 \\
Jabatan & 0,2 & 1 & 0,333 \\
Golongan & 0,333 & 3 & 1 \\
\hline
\end{tabular}

Berdasarkan didapat hasil dari Tabel 2 adalah masa kerja-masa kerja terdapat nilai 1, masa kerja-jabatan terdapat nilai 5, masa kerja-golongan terdapat nilai 3 sampai pada golongan- golongan terdapat nilai 1 .

\section{Sintesis}

Berdasarkan hasil dari tabel sebelumnya yaitu Tabel 2 sehingga didapat Tabel 3 yaitu diperoleh dari matriks atau Tabel 2 sehingga dapat dilihat yang terdapat pada tabel di bawah ini:

a. Menjumlahkan nilai-nilai dari setiap kolom pada matriks

Tabel 3. Nilai Matriks Kriteria Yang di Jumlahkan

\begin{tabular}{lccc}
\hline & Masa Kerja & Jabatan & Golongan \\
\hline Masa Kerja & 1 & 5 & 3 \\
Jabatan & 0,2 & 1 & 0,333 \\
Golongan & 0,333 & 3 & 1 \\
Jumlah & 1,533 & 9 & 4,333 \\
\hline
\end{tabular}

1. Kolom masa kerja $(1 / 1,533=0,652)+(0,2 / 1,533=0,130)+(0,333 / 1,533=0,217)$ 
2. Kolom jabatan

$(5 / 9=0,555)+(1 / 9=0,111)+(3 / 9=0,333)$

3. Kolom golongan

$(3 / 4,333=0,692)+(0,333 / 4,333=0,076)+(1 / 4,333=0,230)$

b. Membagi setiap nilai dari kolom yang bersangkutan untuk memperoleh hasil matriks yang optimal seperti kolom masa kerja. Pada baris pertama kolom masa kerja terdapat nilai 1 dan jumlah nilai kolom masa kerja 1,533 sehingga diperoleh 1/1,533, pada baris keduan kolom masa kerja adalah 0,3 dan jumlah nilai kolom masa kerja adalah 1,533 sehingga diperoleh 0,2/1,533, baris ketiga kolom masa kerja adalah 0,333 dan jumlah kolom masa kerja 1,533 sehingga didapat $0,333 \backslash 1,533$. Dan seterusnya

1. Baris masa kerja : $0,652+0,555+0,692=1,899$

2. Baris jabatan :0,130+0,111+0,076=0,317

3. Baris golongan : $0,217+0,333+0,230=0,78$

c. Menjumlahkan nilai-nilai dari setiap baris dan membaginya dengan jumlah elemen untuk mendapatkan nilai prioritas. Menjumlah hasil dari nilai pada setiap kolom yang berasa di atas yaitu pada masa kerja 0,652, 0,555 dan 0,692 dan seterusnya. Selanjutnya hasil penjumlahan nilai setiap baris dibagi dengan jumlah kriteria yaitu 3, berikut perhitungannya:

1. Prioritas untuk masa kerja : $1,899 / 3=0,633$

2. Prioritas untuk jabatan : $0,317 / 3=0,105$

3. Prioritas untuk golongan $: 0,78 / 3=0,26$

4. Perhitungan Rasio Konsistensi

Berikut ini langkah-langkah dalam menghitung rasio konsistensi :

1. Kalikan setiap nilai pada kolom pertama dengan prioritas relatif elemen pertama, nilai pada kolom kedua dengan prioritas kedua dan seterusnya, akan diperoleh

a. Kolom masa kerja :

$(1 \times 0,633=0,633)+(0,2 \times 0,633=0,126)+(0,333 \times 0,633=0,210)$

b. Kolom jabatan :

$(5 \times 0,105=0,525)+(1 \times 0,105=0,105)+(3 \times 0,105=0,315)$

c. Kolom golongan

$(3 \times 0,26=0,78)+(0,333 \times 0,26=0,086)+(1 \times 0,26=0,26)$

2. Hasil perkalian di atas dijumlahkan setiap baris

a. Baris masa kerja : 0,633 +0,525+0,78=1,938

b. Baris jabatan : $0,126+0,105+0,086=0,317$

c. Baris golongan : $0,210+0,315+0,26=0,785$

3. Hasil dari penjumlahan baris dibagi dengan elemen prioritas relative yang bersangkutan. Dihitung dengan rumus berikut :

a. Baris masa kerja : 1,938/0,633 = 3,061

b. Baris jabatan : 0,317/0,105 $=3,019$

c. Baris golongan : $0,785 / 0,26=3,019$ 
4. Jumlahkan hasil bagi di atas dengan banyaknya elemen yang ada. Hasilnya disebut $\lambda_{\text {maks }}$

$\lambda_{\text {maks }}=9,099$

5. Menghitung Consistency Index (CI) dengan rumus :

Jumlah kriteria $(\mathrm{n})=3$

Maka $\lambda_{\text {maks }}\left(\frac{\text { jumlah }}{n}\right): 3,033$

6. $C I$ (Consistency Index $)=\left(\frac{\lambda_{\text {maks }-m}}{n-1}\right)$

Maka $C I:\left(\frac{\lambda_{m a k s-n}}{n-1}\right)=0,016$

7. $C R($ Consistency Ratio $)=\left(\frac{C I}{I R}\right)$ dimana $I R$ adalah Indeks Random Maka $C R=\frac{C I}{I R}=0,027$

Berdasarkan nilai dar $C R$ adalah 0,027 sehingga $C R<0.1$, maka rasio konsistensi dapat diterima. Dimana jika cr lebih besar dari 0.1 maka akan diterima dan jika lebih kecil maka akan ditolak.

4.2 Menentukan Nilai pada Alternatif untuk Kriteria Masa Kerja

Berdasarkan hasil analisis wawancara yang dilakukan menunjukan bahwa kriteria masa kerja sebagai berikut:

1. Membuat Matriks Perbandingan pada Alternatif untuk Kriteria Masa Kerja Tabel 4. Matriks Perbandingan Berpasangan Alternatif

\begin{tabular}{cccccc}
\hline & $\mathrm{A}$ & $\mathrm{B}$ & $\mathrm{C}$ & $\mathrm{D}$ & $\mathrm{E}$ \\
\hline $\mathrm{A}$ & 1 & $1 / 5$ & $1 / 3$ & $1 / 5$ & $1 / 3$ \\
$\mathrm{~B}$ & 5 & 1 & 3 & $1 / 3$ & 3 \\
$\mathrm{C}$ & 3 & $1 / 3$ & 1 & $1 / 7$ & $1 / 3$ \\
$\mathrm{D}$ & 5 & 3 & 7 & 1 & 3 \\
$\mathrm{E}$ & 3 & $1 / 3$ & 3 & $1 / 3$ & 1 \\
\hline
\end{tabular}

Sumber : wawancara dengan pimpinan

Berdasarkan hasil dari Tabel 4 di atas sehingga diperoleh Tabel 5 seperti yang terlihat di bawah ini :

Tabel 5. Matriks Perbandingan Alternatif yang Disederhanakan

\begin{tabular}{cccccc}
\hline & A & B & C & D & E \\
\hline A & 1 & 0,2 & 0,333 & 0,2 & 0,333 \\
B & 5 & 1 & 3 & 0,333 & 3 \\
C & 3 & 0,333 & 1 & 0,142 & 0,333 \\
D & 5 & 3 & 7 & 1 & 3 \\
E & 3 & 0,333 & 3 & 0,333 & 1 \\
\hline
\end{tabular}

2. Sintesis

Hal-hal yang dilakukan dalam langkah ini adalah :

a. Menjumlahkan nilai-nilai dari setiap kolom pada matriks 
Tabel 6. Nilai Matriks Alternatif yang Dijumlahkan

\begin{tabular}{cccccc}
\hline & A & B & C & D & E \\
\hline A & 1 & 0,2 & 0,333 & 0,2 & 0,333 \\
B & 5 & 1 & 3 & 0,333 & 3 \\
C & 3 & 0,333 & 1 & 0,142 & 0,333 \\
D & 5 & 3 & 7 & 1 & 3 \\
E & 3 & 0,333 & 3 & 0,333 & 1 \\
Jumlah & 17 & 4,866 & 14,333 & 2,008 & 7,666 \\
\hline
\end{tabular}

Tabel 7. Matriks Nilai Alternatif untuk Kriteria Masa Kerja

\begin{tabular}{cccccccc}
\hline & A & B & C & D & E & Jumlah & Prioritas \\
\hline A & 0,058 & 0,041 & 0,023 & 0,099 & 0,043 & & 0,052 \\
B & 0,294 & 0,205 & 0,209 & 0,165 & 0,391 & 1,264 & 0,252 \\
C & 0,176 & 0,068 & 0,069 & 0,070 & 0,043 & 0,426 & 0,085 \\
D & 0,294 & 0,616 & 0,488 & 0,498 & 0,391 & 2,287 & 0,457 \\
E & 0,176 & 0,068 & 0,209 & 0,165 & 0,130 & 0,748 & 0,149 \\
\hline
\end{tabular}

3. Perhitungan Rasio Konsistensi

Berikut ini langkah-langkah dalam menghitung rasio konsistensi :

1. Kalikan setiap nilai pada kolom pertama dengan prioritas relatif elemen pertama, nilai pada kolom kedua dengan prioritas kedua dan seterusnya, akan diperoleh :

a. Kolom A :

$(1 \times 0,052=0,052)+(5 \times 0,052=0,260)+(3 \times 0,052=0,156)+(5 \times 0,052=0,260)+$

$(3 \times 0,052=0,156)$

b. Kolom B :

$(0,2 \times 0,252=0,050)+(1 \times 0,252=0,252)+(0,333 \times 0,252=0,083)+(3 \times 0,252=0,756)+$

$(0,333 \times 0,252=0,083)$

c. Kolom C :

$(0,333 \times 0,085=0,028)+(3 \times 0,085=0,255)+(1 \times 0,085=0,085)+(7 \times 0,085=0,595)+$ $(3 \times 0,085=0,255)$

2. Hasil perkalian di atas dijumlahkan setiap baris
a. Baris A : 0,052+0,050+0,028+0,091+0,049=0,270
b. Baris B : $0,260+0,252+0,255+0,152+0,447=1,366$
c. Baris C :0,156+0,083+0,085+0,064+0,049=0,437

3. Hasil dari penjumlahan baris dibagi dengan elemen prioritas relatif yang bersangkutan. Dihitung dengan rumus berikut :

a. Baris A : 0,270/0,052 = 5,192 
b. Baris $B$ : 1,366/0,252 = 5,420

c. Baris $C: 0,437 / 0,085=5,141$

1. Jumlahkan hasil bagi di atas dengan banyaknya elemen yang ada. Hasilnya disebut $\lambda_{\text {maks }}$ $\lambda_{\text {maks }}=26,824$

2. Menghitung Consistency Index (CI) dengan rumus :

3. Jumlah kriteria $(\mathrm{n})=5$

Maka $\lambda_{\text {maks }}\left(\frac{\text { jumlah }}{n}\right): 5,364$

4. $C R($ Consistency Ratio $)=\left(\frac{C I}{I R}\right)$ dimana $I R$ adalah Indeks Random Maka $C R=\frac{C I}{I R}=0,081$

Nilai $I R$ didapat berdasarkan tabel.

Selanjutnya, karena nilai $C R<0.1$, maka rasio konsistensi dapat diterima.

4.3 Menentukan Nilai pada Alternatif untuk Kriteria Golongan

1. Membuat Matriks Perbandingan pada Alternatif untuk Kriteria Golongan

Tabel 8. Matriks Perbandingan Berpasangan Alternatif

\begin{tabular}{llllll}
\hline & A & B & C & D & E \\
\hline A & 1 & $1 / 5$ & $1 / 5$ & $1 / 5$ & $1 / 7$ \\
B & 5 & 1 & 1 & 1 & $1 / 3$ \\
C & 5 & $1 / 1$ & 1 & 1 & $1 / 3$ \\
D & 5 & $1 / 1$ & $1 / 1$ & 1 & $1 / 3$ \\
E & 7 & 3 & 3 & 3 & 1 \\
\hline
\end{tabular}

Berdasarkan hasil dari Tabel 8 di atas sehingga diperoleh tabel 2 seperti yang terlihat di bawah ini :

Tabel 9. Matriks Perbandingan Alternatif yang Disederhanakan

\begin{tabular}{llllll}
\hline & A & B & C & D & E \\
\hline A & 1 & 0,2 & 0,2 & 0,2 & 0,142 \\
B & 5 & 1 & 1 & 1 & 0,333 \\
C & 5 & 1 & 1 & 1 & 0,333 \\
D & 5 & 1 & 1 & 1 & 0,333 \\
E & 7 & 3 & 3 & 3 & 1 \\
\hline
\end{tabular}

2. Sintesis

Hal-hal yang dilakukan dalam langkah ini adalah :

a. Menjumlahkan nilai-nilai dari setiap kolom pada matriks 
Tabel 10. Nilai Matriks Alternatif yang Dijumlahkan

\begin{tabular}{llllll}
\hline & A & B & C & D & E \\
\hline A & 1 & 0,2 & 0,2 & 0,2 & 0,142 \\
B & 5 & 1 & 1 & 1 & 0,333 \\
C & 5 & 1 & 1 & 1 & 0,333 \\
D & 5 & 1 & 1 & 1 & 0,333 \\
E & 7 & 3 & 3 & 3 & 1 \\
Jumlah & 23 & 6,2 & 6,2 & 6,2 & 2,141 \\
\hline
\end{tabular}

b. Membagi setiap nilai dari kolom yang bersangkutan untuk memperoleh normalisasi matriks.

1. Kolom A :

$(1 / 2,116=0,472)+(0,333 / 2,116=0,157)+(0,333 / 2,116=0,157)+(0,25 / 2,116=0,118)+$ $(0,2 / 2,116=0.094)$

2. Kolom B :

$(3 / 5,033=0,596)+(1 / 5,033=0,198)+(0,333 / 5,033=0,066)+(0,5 / 5,033=0,099)+$ $(0,2 / 5,033=0,039)$

3. Kolom C :

$$
\begin{aligned}
& (3 / 7,533=0,398)+(3 / 7,533=0,398)+(1 / 7,533=0,132)+(0,333 / 7,533=0,044)+ \\
& (0,2 / 7,533=0,026)
\end{aligned}
$$

3. Menjumlahkan nilai-nilai dari setiap baris dan membaginya dengan jumlah elemen untuk mendapatkan nilai prioritas.

1. Baris $\mathrm{A}: 0,472+0,596+0,398+0,387+0,263=2,116$

2. Baris $B: 0,157+0,198+0,398+0,193+0,263=1,209$

3. Baris C : $0,157+0,066+0,132+0,290+0,263=0,908$

Selanjutnya hasil penjumlahan nilai setiap baris dibagi dengan jumlah kriteria yaitu 5, berikut perhitungannya:

1. Prioritas untuk $A: 2,116 / 5=0,423$

2. Prioritas untuk $B: 1,209 / 5=0,241$

3. Prioritas untuk $C: 0,908 / 5=0,181$

Tabel 11 Matriks Nilai Alternatif untuk Kriteria Golongan

\begin{tabular}{cccccccc}
\hline & A & B & C & D & E & Jumlah & Prioritas \\
\hline A & 0,043 & 0,032 & 0,032 & 0,032 & 0,066 & 0,205 & 0,041 \\
B & 0,086 & 0,161 & 0,161 & 0,161 & 0,155 & 0,724 & 0,144 \\
C & 0,086 & 0,161 & 0,161 & 0,161 & 0,155 & 0,724 & 0,144 \\
D & 0,086 & 0,161 & 0,161 & 0,161 & 0,155 & 0,724 & 0,144 \\
E & 0,304 & 0,483 & 0,483 & 0,483 & 0,467 & 2,220 & 0,444 \\
\hline
\end{tabular}

3. Perhitungan Rasio Konsistensi

Berikut ini langkah-langkah dalam menghitung rasio konsistensi :

1. Kalikan setiap nilai pada kolom pertama dengan prioritas relatif elemen pertama, nilai pada kolom kedua dengan prioritas kedua dan seterusnya, akan diperoleh :

a. Kolom A : 
$(1 \times 0,423=0,423)+(0,333 \times 0,423=0,140)+(0,333 \times 0,423=0,140)+(0,25 \times 0,423=$ $0,105)+(0,2 \times 0,423=0,084)$

b. Kolom B :

$(3 \times 0,241=0,723)+(1 \times 0,241=0,241)+(0,333 \times 0,241=0,080)+(0,5 \times 0,241=0,120)$

$+(0,2 \times 0,241=0,048)$

c. Kolom C :

$(3 \times 0,181=0,543)+(3 \times 0,181=0,543)+(1 \times 0,181=0,181)+(0,333 \times 0,181=0,060)+$

$(0,2 \times 0,181=0,036)$

2. Hasil perkalian di atas dijumlahkan setiap baris
a. Baris $\mathrm{A}: 0,423+0,723+0,543+0,408+0,24=2,337$
b. Baris B : $0,140+0,241+0,543+0,204+0,24=1,368$
c. Baris C : $0,140+0,080+0,181+0,306+0,24=0,947$

3. Hasil dari penjumlahan baris dibagi dengan elemen prioritas relative yang bersangkutan. Dihitung dengan rumus berikut :
a. Baris $\mathrm{A}: 2,337 / 0,423=5,524$
b. Baris $B: 1,368 / 0,241=5,676$
c. Baris $C: 0,947 / 0,181=5,232$

4. Jumlahkan hasil bagi di atas dengan banyaknya elemen yang ada. Hasilnya disebut $\lambda_{\text {maks }}$ $\lambda_{\text {maks }}=25,482$

5. Menghitung Consistency Index (CI) dengan rumus :

Jumlah kriteria $(\mathrm{n})=5$

Maka $\lambda_{\text {maks }}\left(\frac{\text { jumlah }}{n}\right): 5,096$

6. CI (Consistency Index $)=\left(\frac{\lambda_{\text {maks }-n}}{n-1}\right)$

Maka $C I:\left(\frac{\lambda_{\text {maks }-\pi}}{n-1}\right)=0,096$

7. $C R($ Consistency Ratio $)=\left(\frac{C I}{I R}\right)$ dimana $I R$ adalah Indeks Random Maka $C R=\frac{C I}{I R}=0,021$

Nilai $I R$ di dapat berdasarkan tabel

Selanjutnya, karena nilai $C R<0.1$, maka rasio konsistensi dapat diterima.

4.4 Perhitungan Total Rangking

Dari seluruh perhitugan yang dilakukan terhadap ke 3 kriteria yakni masa kerja, jabatan, dan golongan, yang selanjutnya dikalikan dengan alternatif prioritas.Dengan demikian kita peroleh tabel hubungan antara kriteria dengan alternatif.

Tabel 12. Matriks Hubungan antara Kriteria dengan Alternatif

\begin{tabular}{lccc}
\hline & Masa kerja & Jabatan & Golongan \\
\hline A & 0,052 & 0,423 & 0,041 \\
B & 0,252 & 0,241 & 0,144 \\
C & 0,085 & 0,181 & 0,144 \\
D & 0,457 & 0,102 & 0,144 \\
E & 0,149 & 0,048 & 0,444 \\
\hline
\end{tabular}


Dari hasil perhitungan pada tabel di atas diperoleh:

$$
\begin{aligned}
& A=(1 / 23=0,043)+(5 / 23=0,086)+(5 / 23=0,086)+(5 / 23=0,086)+(7 / 23=0,304) \\
& B=(0,2 / 6,2=0,032)+(1 / 6,2=0,161)+(1 / 6,2=0,161)+(1 / 6,2=0,161)+(3 / 6,2=0,483) \\
& C=(0,2 / 6,2=0,032)+(1 / 6,2=0,161)+(1 / 6,2=0,161)+(1 / 6,2=0,161)+(3 / 6,2=0,483)
\end{aligned}
$$

Dari hasil di atas diketahui bahwa urutan prioritas pada gaji bonus karyawan di PTPN III Sei Putih adalah sebagai berikut:

$\mathrm{D}=$ percaya diri $(0,336)$

$\mathrm{B}=$ disiplin kerja $(0,221)$

$\mathrm{E}=$ kerja sama $(0,214)$

$\mathrm{A}=$ absensi $(0,176)$

$\mathrm{C}=$ tanggung jawab $(0,109)$

\section{Kesimpulan}

Adapun kesimpulan yang saya simpulkan adalah:

1. Berdasarkan penelitian yang telah di lakukan dapat disimpulkan bahwa penerapan metode Analytical Hierarchy Process (AHP) untuk mengetahui urutan prioritas pada gaji bonus karyawan cukup efektif dalam mengatasi penentuan urutan prioritas prioritas pada gaji bonus karyawan di PTPN III Sei Putih.

2. Dari hasil penelitian menggunakan metode Analytical Hierarchy Process (AHP) dapat di simpulkan bahwa urutan prioritas pada gaji bonus karyawan di PTPN III Sei Putih yaitu percaya diri $(0,336)$, disiplin kerja $(0,221)$, kerja sama $(0,214)$, absensi $(0,176)$, tanggung jawab $(0,109)$.

\section{Daftar Pustaka}

[1] Daniel, Rossa, dkk. 2012. Sistem Prediksi Pertandingan Sepak Bola Dengan Metode Analytical Hierarchy Process (AHP). Jurnal Informatika. 2(2): 181.

[2] Dwirja. 2017. Sistem Pendukung Keputusan Penentuan Gaji Bonus pada Restoran KL Express dengan Metode TOPSIS. Jurnal Ilmiah Teknologi dan Informasi ASIA (JITIKA. 11(1): 101.

[3] Nuriadi Manurung. 2017. Sistem Pendukung Keputusan Pemberian Bonus Karyawan Menggunakan Metode AHP. Jurnal Teknologi Informasi. 1(1): 48.

[4] PTPN III. 2017. Perkebunan. http://www.ptpn3.co.id/biskakbn.php?h=bisnis-kami. (29 April 2020).

[5] Agustina Indriani. 2014. Analisis Pengaruh Gaji dan Tunjangan Kesejahteraan Terhadap Produktivitas Kerja Karyawan Operation Dapartment PT. Export Leaf Indonesia. Jurnal Paradigma. 12(1): 41-46.

[6] Sandra Jamu Kuryanti, Novita Indriyati. 2016. Penentuan Bonus pada Karyawan dengan Menggunakan Metode Analytic Network Process. Jurnal umj.

[7] Isbalaikana, Fitri. 2019. Sistem Aplikasi Penentu Gaji Karyawan pada UD. Mebel DM Menggunakan Metode AHP Berbasis Website. Journal of Information Technology and Computer Science (4)1: 27 